\title{
Transmission System Expansion Planning For Indian States: A Proactive and Realistic Approach
}

\author{
G.Balamurali ${ }^{1}$, Dr.K.Thanushkodi ${ }^{2}$ \\ ${ }^{I}$ Tamil Nadu Electricity Board, Chennai-600002, India \\ ${ }^{2}$ Director, Akshaya College of Engineering and Technology, Coimbatore, India
}

\begin{abstract}
The optimum transmission expansion planning is one of the vital areas to be focused in India to deliver the power to the needy States from the surplus States crossing regional boundaries to resolve the current Indian power crisis. This paper presents how the transmission system expansion planning has to be carried-out for an Indian States by presenting the fundamental care approach-listing the issues to be taken care of while preparing transmission expansion plan, realistic approaches for different types of power evacuation system planning, basic principles and key issues of substation planning and network expansion planning to meet multiple objectives. In addition, towards proactive planning, a special analysis on management of reactive power, management of uncertainties and congestion alleviation in the current system are reported. The prime objective of this paper is to develop a proactive and realistic approach for transmission system expansion planning in holistic manner based on the problems experienced by the State/Central Utilities in Transmission System expansion planning. This paper is aimed to disseminate knowledge on practical intricacies involved in Transmission planning by the planners to those who are involved in real time planning as well as academic community.
\end{abstract}

Keywords: Power Evacuation System Planning, Substation Planning, Network Expansion Planning, Reactive Power, Congestion Alleviation, Uncertainty.

\section{Introduction}

Economic development of any country depends largely on the most essential service "Power". Planning and development of power system infrastructure to cater the needs of the people assumes great importance at any point of time. However this task is getting increasingly difficult as the recent days are witnessing an increase in the gap between demand and supply in most of the States of India and meteoric load growth. Dearth in availability of power at the right time has been assessed to be the main problem for this gap which is attributed due to prolonged process of Identification of whether Central /State/ Joint venture / Private Sector generation projects, non-availability of indigenous coal, Environmental clearances, inadequate evacuation facilities, Right of Way and financial instability of the State Electricity Utilities etc. Developing the transmission corridor on time by the State Transmission Utility (STU) or Central Transmission Utility (CTU) or Public Private Partnership (PPP) to evacuate the power from the projects and segregation of corridors viz. State sector, central sector, private sector with provision to interconnect each is an absolute necessity to alleviate congestion and balance the reactive power and help making power available to all the end-users. The goal of relieving the stress on the national grid due to transfer of surplus power across states would also be achieved by appropriate planning.

Several methods have been proposed in literature for transmission system expansion planning from the viewpoints of minimizing investment, maximizing security and improving the optimal utilization of transmission assets. In [1], automated rule based expert system approach to augment the transmission system to alleviate congestion, system augmentations under contingency and reactive power management are proposed. The performance efficiency evaluation of the expansion options to identify an efficient plan out of multiple plans using Probabilistic Load Flow based ceiling index, Composite Cost utilization index, Transmission System Voltage Stability index, Transmission System Dynamic Stability index and Two Point Available Transfer Capability index are suggested in [2].

In [3], the value of transmission grid, the rationale for vertical unbundling, optimal regulatory frame work and merchant transmission are reviewed and concluded vertical separation and strong incentives are conducive to congestion reduction. In [4] the importance of Proactive Network planning (PNP) is emphasized in a real world system where generators are privately owned and investment decisions in generations are not centrally coordinated. A comprehensive transmission expansion planning is presented in [5] by considering physical and operational constraints like power flow limit, power generation limit, right of way and bus voltage angle limit to achieve optimal planning cost, increased reliability and reduced transmission losses.

The inadequacies of traditional transmission expansion planning practices followed and major challenges to transmission planning in the current changing environment of diversity of many new players are 
reviewed in [6]. In [7] the network planner selects the new lines to be built accounting not only for economic issues, but also for the vulnerability of the transmission network against a set of credible intentional outages and resulting vulnerability and economic constrained transmission expansion planning problem is formulated as a mixed integer linear program. The challenges in integrating wind power into grid and strategies to tackle the challenges are deliberated in [8]. The events and direct causes of large blackouts 2003 in US/Canada and Europe are reviewed and suggested the countermeasures for blackout prevention in [9]. How the transmission network planning has to be done to reduce the short circuit levels are investigated in [10]. The goal of obtaining maximum of network adequacy with lowest expansion cost using decimal codification genetic algorithm is studied in[11,12].

Further, in recent days, the incorporation of FACTS controllers for increasing the utilization of transmission line to the thermal limit by modifying the line impedance and to improve the voltage profile by providing or absorbing reactive power support are getting more focus in the technology advancement era. A comprehensive survey of incorporation of FACTS controllers is presented in [13]. The optimal location of FACTS controllers to improve system loadability with minimum cost of installation of FACTS controllers through application of particle swarm optimization technique is dealt in [14]. In [15] the application of Ant Colony Optimization to solve a static Transmission Expansion Planning problem based on DC power flow model is proposed. Two new criteria i.e., the social welfare percentage and congestion cost percentage are defined in [16] and used for the full and true evaluation of the market based transmission expansion planning. The probabilistic methodology for optimal transmission expansion under uncertain power market condition is proposed in [17].

These approaches are not ideally suited for transmission planning of Indian States. The reasons for this are as follows:

- Practical issues like Inter State Transmission System (ISTS) constraints, islanding scheme, peak and off peak management with energy storage options, meeting loss reduction target and renewable energy integration etc., taken into account by the State and Central Utilities followed in practice while planning for transmission system expansion in India are not discussed in full by the researchers.

- Transmission system development for different categories of generation projects and network expansion with different objectives in Indian States are not fully explored by current researches.

Salient features of the proposed approach are as follows:

(1) Fundamental care approach, i.e., basic issues to be taken care while preparing transmission system expansion planning

(2) Devising proactive and realistic plans for power evacuation

(3) Substation planning - Basic Principles and key issues

(4) Formulating proactive and realistic network expansion planning

(5) Managing reactive power, congestion alleviation and uncertainties

The prime objective of this paper is to build the knowledge necessary to face current challenges in transmission expansion planning in India. This paper is aimed to disseminate the knowledge on practical intricacies involved in Transmission Planning by the planners to those who are involved in real time planning as well as academic community.

The paper is organized as follows: Section 2 presents the fundamental care approach explaining the basics of inputs required for planning the expansion/improvisation of the existing transmission network. Section 3 speaks about proactive and realistic approach for planning of transmission system with special focus to generation project, substation planning, network expansion planning, reactive power management, congestion alleviation management and uncertainties management. Section 4 ends with Conclusion.

\section{Fundamental Care Approach}

Preparation of development plans for any transmission system requires care on the following basic issues depicted in Fig.1. 
Fig.1. Fundamental Care required for Transmission Planning

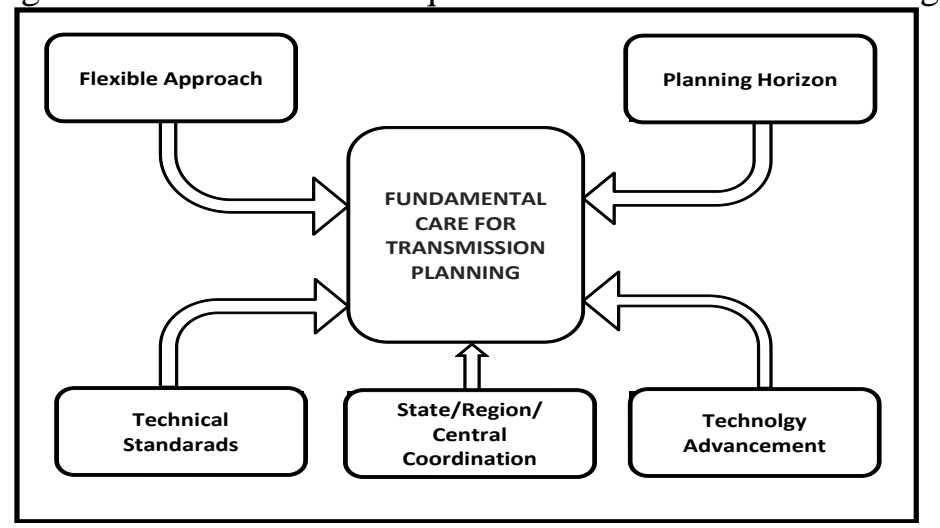

\subsection{Infrastructure Planning Horizon}

Plan period for basic infrastructure for all sector is 5 years in both State and Central Governments of India. Review of the plan based on the actual progress and suggestion for further expansion if necessary are made by the Central and State Planning Commission. The Commissions obtain approvals from the Ministry which accords them after strict review again. The Planning Commission of India and State Planning Commissions including concerned Ministries review the progress of implementation of the developed plan every year. To this reference, the Power System infrastructure development is to be planned for a period of 5 years for the specific plan period with short term milestones to be achieved every year.

\subsection{Flexible Approach}

The development of any system for a plan period is subjected to changes while progressing based on the needs of the sudden changes in internal and external environment of the system such as Government policy on market development, social obligations, community development, nonprofit development, green Energy development, regulatory and reform requirements etc., Therefore any system development has to be flexible enough to accommodate the possible changes that may occur during the course of plan period.

\subsection{Technology Advancement Approach}

The benefit of technology advancement such as considering higher capacity infrastructure placement in place of existing infrastructure before planning for new one have to be explored by referring to international associations. Similarly, inviting global bids for the new infrastructure development and technology collaboration leads to new way of doing the regular planning such as new standard in capacity like $800 \mathrm{MW}$ instead of regular 210 or 500 MW Generator etc.,. Thus, harnessing technology benefits is vital for success of effective planning.

\subsection{Meeting Technical Standards}

In India, CEA provides guidelines for development of transmission Infrastructure with reference to technical requirements. Similarly, Utilities have to maintain the system as per the Indian Electricity Grid Code (IEGC)[18]. Also, Power System Equipment manufacturers maintain certain design criteria specific to equipments such as MVA capacity, Amps capacity, MVAR capacity, Voltage levels etc.,. All such applicable standards with compatibility to suit the existing networks have to be taken care before planning the infrastructure.

\subsection{State, Regional and Central Level Coordination requirements}

The power generating stations are established nearer to resources. But, power evacuation system and transmission system are developed based on the proportional share of power to the constituents of the particular region and needs of the other regions. This necessitates proper coordination between states within and outside the regions and Central Utilities and authorities. The State and Central Utilities are committed to provide additional transmission infrastructure facility to facilitate power trading.

\section{Proactive and Realistic Approach for Planning of Transmission System}

The formulation of Transmission system Expansion Planning (TEP) involves various components shown in Fig.2. The components are elaborated in the following sections. 
Fig.2. Components of Transmission System Expansion Planning

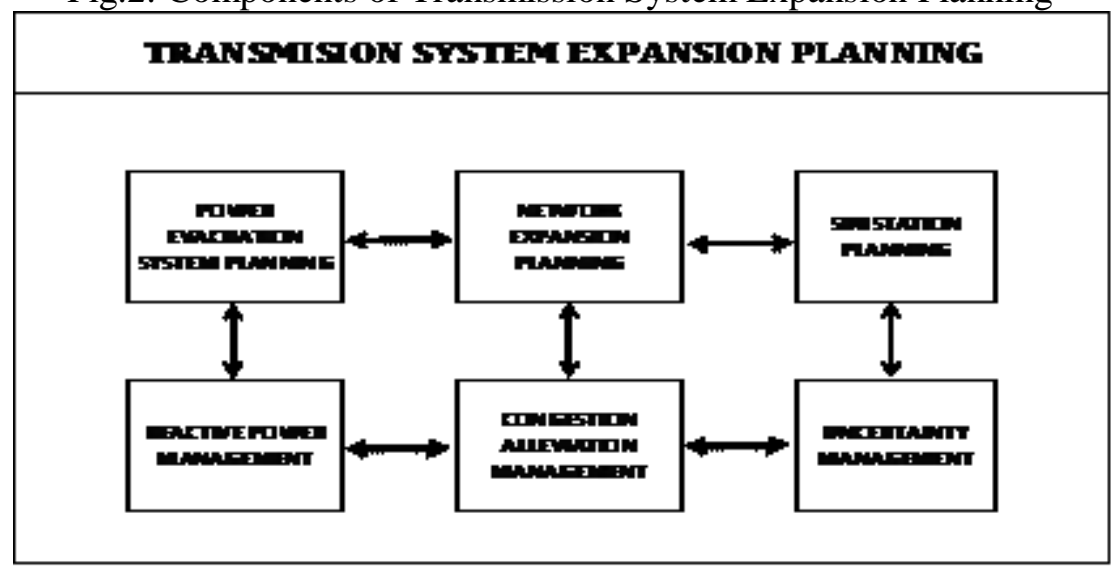

\subsection{Power Evacuation System Planning}

\subsubsection{New/Replacement/Expansion State Sector Generation Projects}

The transmission system for evacuation of power from the new generation projects of State GENCOs as well as replacement of old obsolete stations have to be planned and developed in accordance to the commissioning schedule of the generation project. Similarly transmission system for evacuation of power from Expansion Generation Projects of existing Plants have to be designed by optimally utilizing the existing transmission system and Right of Way by converting Single Circuit to Double Circuit or Multiple Circuit transmission system or UHV system.

\subsubsection{Central Sector Generation Projects:}

The Central Sector Projects are located at different States and the power from these projects is shared among the constituents and the power transfer from one state to other are happening through displacement method, thereby minimizing the power transfer through ISTS lines. This has to be viewed with special attention to ensure the availability of ISTS lines for transfer of power under different practical scenario such as additional allocation from unallocated power in Central Pool, reduced drawal from allocated share due to renewable energy integration and sudden changes in allocation under emergencies and also due to changes in network conditions.

\subsubsection{Distributed Renewable Energy (RE) Projects}

In recent years, Government of India is giving special focus to promote renewable energy projects. RE projects are normally small capacity in nature and distributed. This attribute of RE projects facilitates the evacuation of power from these projects at voltage level of $11 \mathrm{kV}, 22 \mathrm{kV}$ or $33 \mathrm{kV}$ network connected to the nearby $110 \mathrm{kV}$ Substation. These type of RE projects supplying power to meet the demand of the load centre locally, reduces the system losses through transfer of power from distant generating stations. For large size, Group of Wind Projects and Solar Parks the power evacuation system have to be designed in such a way that the utilization of the Green Corridor during off season can be taken care by properly connecting nearby lines in order to avoid condition of no load in the corridor during off season resulting in over voltage issues.

\subsubsection{Competitive Bidding based Generation Projects}

The Power purchase in India is largely done through competitive bidding basis which is also called the Case-I and Case-II bidding. Currently major power purchases are contracted through this route by the DISCOM. The development of transmission system for these Case-I and Case-II Generation Projects are not routine as the purchasing DISCOMs and quantum of purchase are not known during the development of Generation Projects. This needs special attention while developing transmission system. This has to be looked at differently by analysing the demand supply gap of State where the project is proposed and the possible other purchasers, by analyzing the demand supply gap of other States. Accordingly, the CTUs and STUs have to develop transmission system to meet the proposed generation addition for the plan period.

\subsubsection{Power Pool to evacuate power from large capacity plants}

Unlike traditional Utilities, Merchant Power plants[19] compete for customers and absorb the full market risk. There are no guarantees that they will have a minimum off take of their output. MPP operating competitively help assure that power is produced efficiently and supplied to locations where it is needed most. They must respond to market needs. Hence while developing the evacuation system for MPPs, demand supply 
gap wherever persists higher has to be factored into the transmission planning for deciding the regional grid strengthening to export to regional grid apart from possible consumption through State Grid where the Generator is located. Generally different MPPs are connected to $765 / 400 \mathrm{kV}$ pooling station which in turn is connected to regional grid to fully evacuate the power without constraints.

\subsubsection{Possibility of Interconnecting of Projects}

The possible interconnecting of projects have to be studied for availing start-up power and improving the reliability of power evacuation during outage of any of the evacuation feeders. This will also enhance the utilization of evacuation feeders and reduce the necessity of more bay provision at substations and avoids laying of new lines for every expansion project/new adjacent project.

\subsection{Substation Planning}

\subsubsection{Basic Principles}

The proposal of new substation has to be evolved based on the load growth in the specified area with respect to existing capacity of the substations in that area as well as margin availability to meet the demand growth and to improve the voltage profile, to provide relief to neighboring substations. The power system planner should give adequate care and focus on power transfer capability of the system while designing the upstream Pooling and transmission substations for evacuation of power from wind farm clusters.

\subsubsection{Key Issues}

Feeders

The nearby lines may be made Line In Line Out (LILO) to the new substation as two connectivity/sources to optimize the existing infrastructure instead of building new lines. Also linking of important substations is to be explored to improve reliability. The number of feeders in power evacuation substations shall be optimized by exploring the possibilities of interconnecting smaller projects. In practice a minimum of two incoming feeders and four outgoing feeders are to be specified for any new substations. For substations feeding essential services, the LV bus should have interconnections with nearby substations so as to ensure uninterrupted supply to essential loads even during main source failure.

\section{Transformers}

The decision on size and number of transformers is usually selected such a way that during outage of one transformer, the other transformers should be adequate to cater short time overloading. The total transformer capacity in any substations of $400 \mathrm{kV}, 230 \mathrm{kV}$ or $110 \mathrm{kV}$ level normally shall not exceed 1000MVA, 320MVA and 150MVA respectively. The load transfer to the nearby substations to manage in the event of outage of substation elements or Line Clear is to be taken care while planning for transformer capacity. On any account, there should be at least $20 \%$ capacity margin in the transformers to manage contingencies.

\section{Fault level calculation}

Fault MVA calculations are essential to decide the breaker's rupturing capacity. Changes in the network configuration have impact on fault level of the system. System planning should identify the possibilities to limit the increasing trend on fault level so as to avoid unnecessary expenditure on replacement of protective equipments.

\subsection{Network Expansion Planning}

The network expansion planning has to take care of the following objectives indicted in Fig. 3 to manage the grid efficiently.

\section{Fig.3. Objectives of Network Expansion Planning}

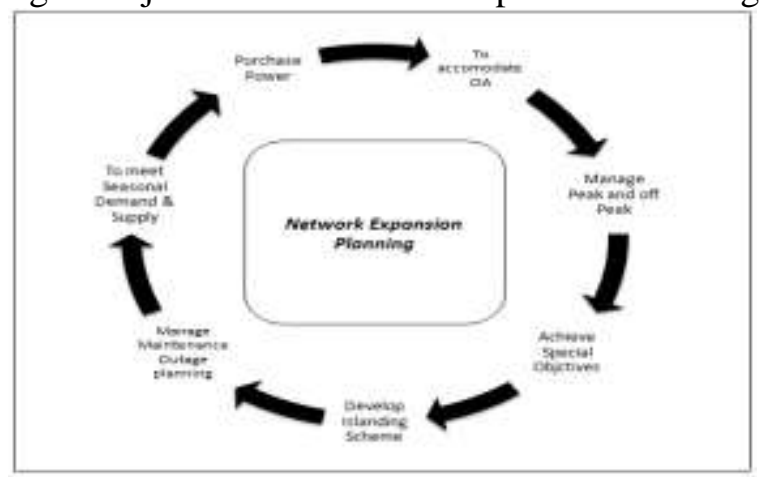




\subsubsection{To meet variation in seasonal demand and supply}

Power demand varies with seasons. In India, five different seasons, viz, April to June, July to September, October \& November, December to February and March are specified in the regulations for Transmission Pricing Strategy [20]. The peak and off peak of different areas of the State may occur at different time for any particular season and hence the loading of system may vary widely during different season and at different timings. Thus to check the adequacy of infrastructure, the system has to be analyzed in wide range for different season scenarios to factor the diversity of loads. The multiple scenario load flow analysis is to be conducted for existing and future network. This process facilitates the identification of the weak points where the system requires strengthening and development.

\subsubsection{To Purchase Power}

To minimize the gap between the demand -supply and to manage the emergency power deficit due to outage of major plants, Indian Power utilities are purchasing power from open market through Power exchanges like IEX, PXIL[21]. Thus the planners have to look into historical data of region wise power transaction through power exchanges and anticipated power trading in such a way to provide adequate transmission capacity margin for power purchase.

\subsection{To accommodate open access customers:}

Customers are permitted to inject power to grid or draw power from grid under the short term, medium term and long term Open Access policy. Under this changing scenario, transmission planning has to take care of the needs of such Open Access customers with knowledge of their points of injection and points of drawal during the plan period. Further system development should ensure availability of power to open access customers even during load shedding when there are deficits in the system.

\subsubsection{To manage peak and off peak loads with energy storage options}

The network planning is to be made for meeting the peak load and off peak load conditions. Peak load has to be served without any congestion or violation of voltage limit. The energy storage schemes such as pumped storage and battery storage schemes require additional transmission capacity to cater for the dual mode operations.

\subsubsection{To achieve special objectives}

The Utility every year prepares System Improvement Plan to meet certain regulatory requirements with primary objectives such as Loss reduction or improvement of quality of supply etc., and schemes for operational flexibility through system reconfiguration. Such special objective requirements are to be factored into the network expansion planning.

\subsubsection{To avoid total blackout by developing islanding scheme}

The network augmentation should be designed in such a way to enhance the islanding action during system collapse. The power evacuation schemes for the new power projects should form part of the existing islanding scheme or otherwise new islanding scheme shall be developed to take care of system reliability.

\subsubsection{To manage maintenance outage planning:}

The hydel power generation largely depends on head and availability of water, as well as irrigation or non irrigation based operation decided by the Public Works department or Electric Utility in India. Wind power is seasonal and highly variable. Generation is maximum during peak wind seasons from May to September and is almost nil during rest of the year. Maintenance of Thermal Stations are generally taken up from July to December based on the availability of Hydro and Wind power. The maintenance scheduling of generating units, major substations and transmission lines is prepared based on the availability of alternate sources and adequacy of alternate transmission facility. The transmission planning shall be developed giving due consideration in enhancing the transmission capacity margin to facilitate maintenance scheduling without necessitating the load shedding or rescheduling of generation.

\subsection{Reactive Power Management}

\subsubsection{VAr Billing}

Injecting or drawing of reactive power is done preferably on the distribution load point itself, wherever possible in addition to meet the reactive power requirement of network at appropriate point. This will minimize the need for reactive power exchange between ISTS and STU boundaries. The voltage at the particular bus in boundary points is taken as reference for determining the Var drawal charges to the recipient thereby discouraging the recipient to draw reactive power from ISTS end. Similarly Var injection into the ISTS 
boundary points is supported with reference to the voltage at the particular bus in boundary points. STU is billed at the rate of 10 paise per kVArh for VAr drawal when voltage at the metering end is below $97 \%$. In the same way, STU is earning revenue for drawal of VAr when voltage is above $103 \%$. VAr injection when voltage is above $103 \%$ and $\mathrm{VAr}$ injection when voltage is below $97 \%$ is considered equally for billing/payment[18]. Generally, STU has to minimize the reactive power drawal at the boundary point when the voltage is below $95 \%$ at the boundary point, and is to avoid injecting $\mathrm{VAr}$ when the voltage is above $105 \%$. By analyzing this billing, we can arrive at the additional reactive power support needed by the existing system fairly and plan the system improvement accordingly.

\subsubsection{RPC and RLDC reports}

The Regional Power Committee (RPC)[22] conducts the shunt compensation study annually to assess the shunt compensation requirement for the next year for each constituents in the region based on the current year data during regional peak load condition occuring in the month of March obtained from Regional Load dispatch Centre(RLDC)[23] and Regional Constituents. The data such as list of capacitors in service, likely load growth; new elements scheduled for commissioning during next year are supplied by the constituents of RPC. A weekly report available in the website of RLDC provides information on performance of the Regional grid for the previous 12 weeks. In that report Voltage profile of important substations and sub-stations normally having low /high voltages are also available. From this report the specific area of reactive power support devices broadly to be located can be judged.

\subsubsection{Reactive Power through ICTs:}

Reactive power through ICTs shall be minimal. Normally it should not[24] exceed 10\% of the rating of the ICT. The analysis of reactive power flows through ICTs present in the system will give good plan to locate compensation devices.

\subsection{Congestion Alleviation Management}

Though planning of the network is based on careful study of forecasted demand and anticipated capacity addition, congestion in evacuation of power may arise due to unforeseen outages. Hence the carefully planned network should not collapse but deliver the necessary power through alternative arrangement which are to be part of proactive planning schedule.

\subsubsection{Inter area congestion}

The congestion has to be identified by checking the power flow of intra state tie lines from one major load centre to other major load centre. Thus though no congestion in power evacuation lines of generating stations, congestion may arise in the next stage inter area lines based on the load in that area.

\subsubsection{Congestion due to Infirm Generation Mix}

The renewable energy is infirm in nature leading to sudden increase or drop in power flow in transmission lines and overloading. This has to be identified by considering different generation mix strategies to full wind-full hydro, nil wind-nil hydro, nil wind-full hydro, and full wind-nil hydro with regular thermal generation cases.

\subsubsection{Independent and Inter-dependent Congestion}

The removal of one congestion may reduce the congestion level in other area. Contrary, removal of congestion in one area may not reduce the congestion in other area. Such congestion have to be taken care of while preparing the plan for strengthening of system to avoid the unnecessary investments to create a well balanced network.

\subsubsection{Determination of Congestion}

The line loading limit depends on different factors such as thermal loading, stability and voltage regulation. Thermal loading of conductor is generally dependent on environmental condition such as ambient temperature, solar radiation, wind velocity and conductor characteristics such as maximum design conductor temperature, age of the conductor etc., The maximum permissible line loadings in respect of different conductors normally used in India is indicated [24-25] in the Table-1. Hence any loading above this limit is considered as congestion and adequate planning is to be made to alleviate the congestion 
Table-1 : Maximum permissible line loading

\begin{tabular}{|l|l|l|l|}
\hline \multirow{2}{*}{ Conductor use in practice } & \multicolumn{2}{|c|}{$\begin{array}{c}\text { Limiting Amperes at } \\
\mathrm{T}_{\text {conductor } \max }=75^{0}\end{array}$} & \multirow{2}{*}{$\begin{array}{c}\text { Practical } \\
\text { loading (MW) }\end{array}$} \\
\cline { 2 - 3 } & $\mathrm{T}_{\text {ambient }}=45^{0}$ & $\mathrm{~T}_{\text {ambient }}=40^{\circ}$ & \\
\hline $765 \mathrm{kV}$ Quad Bersimis & $697 \times \mathrm{X} 4$ & $804 \times \mathrm{X} 4$ & 2400 \\
\hline $400 \mathrm{kV}$ ACSR Twin Moose & $595 \times 2$ & $684 \times 2$ & 700 \\
\hline $220 \mathrm{kV}$ ACSR Zebra & 546 & 622 & 200 \\
\hline $132 \mathrm{kV}$ ACSR Panther & 366 & 413 & 80 \\
\hline
\end{tabular}

\subsubsection{Importance of Surge impedance loading}

While the Surge impedance loading, i.e, series reactive loss along the line is equal to shunt capacitive gain, gives the loading capability of the line. The short lines are used to be loaded above surge impedance loading and long lines are loaded to lower than surge impedance loading [24-25]. The SIL at different voltage level is given in the Table- 2 .

Table-2 : SIL at different voltage level

\begin{tabular}{|c|c|c|}
\hline Voltage level & $\begin{array}{c}\text { Number \& size of } \\
\text { conductor }\end{array}$ & $\begin{array}{c}\text { Surge Impedance } \\
\text { Loading (MW) }\end{array}$ \\
\hline $765 \mathrm{kV}$ & $4 \times 686$ & 2250 \\
\hline $400 \mathrm{kV}$ & $2 \times 520$ & 515 \\
\hline $220 \mathrm{kV}$ & 420 & 132 \\
\hline $132 \mathrm{kV}$ & 200 & 50 \\
\hline
\end{tabular}

\subsection{Uncertainty Management}

\subsubsection{Listing Probable Uncertainties}

All the possible uncertainties arising from future generation including distributed generation, demand growth, market players' strategies, changes in policies in power and industrial sector, proposed infusion of Foreign Direct Investment, Increasing Environmental Concern, inter regional transmission constraints, long transmission lead times and Judicial directions on Public interest etc., are to be analyzed in depth in the particular State.

\subsubsection{Factoring the impacts of Uncertainties in Transmission Planning}

The impacts of these uncertainties have to be factored into the transmission planning by giving various alternate options with budget provisions to tackle the uncertainties. Thus the techno-economic transmission expansion plans are to be developed and best option shall be chosen through brainstorming to meet the current and future environment.

\subsection{Significance of the proposed approach}

The proposed approach aims at developing a transmission system planning for different generation projects, substation planning and proactive system network expansion planning by taking into account the issues of Indian power sector environment like seasonal variation in demand \& supply, peak and off peak loads with energy storage options, capacity addition, congestion alleviation, forced and planned outages, special objectives, development of power pool etc. The scrutiny to be conducted for management of reactive power is identified. The fundamental care approach provides the basic issues to be taken care of while planning for system expansion. Thus the proposed approach provides the realistic and proactive approach for transmission system expansion planning in a holistic manner compared to earlier researches.

\section{Conclusions}

This paper presents a proactive and realistic approach for transmission system expansion planning for Indian States in a systematic manner. The important basic issues to be taken care of while developing the transmission expansion planning is presented as fundamental care approach. The network expansion plan for effective management of generation capacity addition, reactive power, load growth, congestion, facilitating private sector projects and dealing uncertainties are dealt in detail. The factors explained in this paper, when taken into account assiduously, will aid in establishment of a model network.

\section{List of Abbreviations and Symbols}

PPP Public Private Partnership 


$\begin{array}{ll}\text { PNP } & \text { Proactive Network planning } \\ \text { FACTS Flexible Alternating Current Transmission system } \\ \text { IEGC } & \text { Indian Electricity Grid Code } \\ \text { CEA } & \text { Central Electricity Authority } \\ \text { TEP } & \text { Transmission system Expansion Planning } \\ \text { MVA } & \text { Mega Volt Ampere } \\ \text { MW } & \text { Megawatt } \\ \text { MVAR Mega } & \text { Volt Ampere Reactive } \\ \text { GENCO Generating Company } \\ \text { TRANSCO } & \text { Transmission Company } \\ \text { DISCOM } & \text { Distribution Company } \\ \text { UHV } & \text { Ultra High Voltage } \\ \text { EHT } & \text { Extra High Voltage } \\ \text { RE } & \text { Renewable Energy } \\ \text { ISTS } & \text { Inter State Transmission System } \\ \text { kV } & \text { Kilo Volt } \\ \text { MPP } & \text { Merchant Power Plant } \\ \text { LILO } & \text { Line In Line Out } \\ \text { LV } & \text { Low Voltage } \\ \text { IEX } & \text { Indian Energy Exchange } \\ \text { PXIL } & \text { Power Exchange India Limited } \\ \text { VAr } & \text { Volt Amps Reactive } \\ \text { kVArh } & \text { kilo Volt Amps Reactive hours } \\ \text { RPC } & \text { Regional Power Committee } \\ \text { RLDC } & \text { Regional Load dispatch Centre } \\ \text { ICT } & \text { Inter Connecting Transformer } \\ \text { SIL } & \text { Surge Impedance Loading } \\ & \end{array}$

\section{References}

[1] Rajeev Kumar Gajbhiye, Devang Naik,Sanjay Dambhare, S.A.Soman, An Expert System Approach for Multi-Year Short Term Transmission System Expansion planning: An Indian Experiene, IEEE Transaction on Power Systems 2008;23(1) :226-237

[2] V.S.K.Murthy Balijepalli , S.A.Khaparde, A Holistic Approach for Transmission System Expansion Planning Studies: An Indian Experience, IEEE Systems Journal, 2011;5(2):199-212

[3] Thomas-Olivier Leautier, Veronique Thelen, Optimal expansion of the power transmission grid: why not?, Journal of Regulatory Economics 2009;36(2):127-153

[4] Enzo E.Sauma and Shmuel S.Oren, Proactive planning and valuation of transmission investments in restructured electricity markets, Journal of Regulatory Economics 2006;30(2):358-387

[5] G.Srinivasulu , B. Subramanyam, A Comprehensive Transmission Expansion Planning for Developing Countries , International Journal Engineering Research and Development 2012; 2(11): 07-13

[6] F.F.Wu , F.L.Zheng, F.S.Wen, Transmission investment and expansion planning in a restructured electricity market, Energy The International Journal 2006; 31: 954-966

[7] Natalia Alguacil, Miguel Carrion , Jose Manuel .Arroyo and, Transmission Network Expansion Planning Under Deliberate Outages, Electrical Power and Energy Systems 2009; 31:553-561.

[8] Debra Justus, Case Study -Wind Power Integration into Electricity Systems, OECD/IEA,France, 2005, 1-32 on line access:http://www.oecd.org/environment /climatechange/34878740.pdf,date of access 01.12.2012

[9] Gunther Beck, Dusan Povh, Dietmar Retzmann, Erwin Teltsch, Global Blackouts-Lessons learned, Siemens AG, Germany, 2011,127 online access

[10] http://www.energy.siemens.com/us/pool/hq/power-transmission/ HVDC/Global_Blackouts.pdf, date of access 01.12.2012

[11] Mahmoud Gilany, Wael Al-Hasawai, Reducing the Short Circuit Levels in Kuwait Transmission Networ(A Case Study), World Academy of Science, Engineering and Technology 2009; 53: 592-596.

[12] M.Mahdavi,E.Mahdavi, Transmission Expansion Planning Considering Network Adequacy and Investment Cost Limitations u sing Genetic Algorithm, International Journal of Electrical and Electronics Engineering 2011;5(4):248-252.

[13] H.Shayeghi, M.Mahdavi, H. Haddadian, DCGA Based Transmission Network Expansion Planning Considering Network Adequacy, International Journal of Information and Communication Engineering 2008; 4(8):591-596.

[14] Bindeshwar Singh, N. K. Sharma, A. N. Tiwari, S.P.Singh, Incorporation of FACTS Controllers in Newton Raphson Load Flow for power flow operation, control and planning; A Comprehensive survey, International Journal on Computer Science and Engineering 2012;2(6): 2117-2124

[15] M.Saravanan, S.Mary Raja Slochanal, P.Venkatesh, J. Prince Stephan Abraham, Application of particle swarm optimization technique for optimal location of FACTS devices considering cost of installation and system loadability. Electric Power System Research 2007;77: 276-283

[16] N.Leeprechanon,P.Limsakul, S.Pothiya, Optimal Transmission Expansion Planning using Ant Colony Optimisation. Journal of Sustainable Energy \& Environment 2010;1: 71-76

[17] Gholam Reza Kamyab, Mahmood Fotuhi Firuzabad ,Masoud Rashidinejad, Market Based Transmission Expansion Planning Under Uncertainty in Bids by Fuzzy Assessment. Journal of Electrical Engineering \&Technology 2012; 7(4):468-479

[18] In-Su Bae, Min-Kyun Son, Jin-O Kim, Optimal Transmission Planning Considering Uncertainties of Power Market. Journal of Electrical Engineering \& Technology 2010; 5(2) : 239-245 
[19] http://www.powermin.nic.in/transmission/pdf/Indian_Electricity_Grid_Code.pdf ,date of access 27.11.2012

[20] http://www.eefi.org/plugins/p2_news/printarticle.php?p2_articleid=431 date of access 28.11.2012

[21] www.nldc.in/IA/FAQ_final.pdf, date of access 07.10.2012

[22] www.iexindia.com, www.powerexindia.com/pxil,date of access 07.10.2012

[23] http://www.srpc.kar.nic.in, date of access07.10.2012

[24] http://www.srldc.in, date of access 07.10.2012

[25] http://www.aptransco.gov.in/webdata/aptransco-technical-reference-book-2011-vol-i.pdf

[26] http://www.cea.nic.in/reports/planning/nep.pdf and http://www.scribd.com/doc/60109979/Manual on Transmission Planning Criteria

\section{Authors Information}

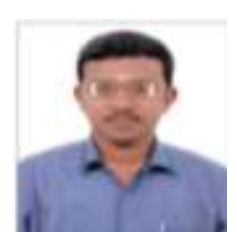

G.Balamurali received his BE degree in Electrical \& Electronics and ME degree in Applied Electronics from Government College of Technology, Coimbatore, Tamil Nadu, India in 1991 and 1993 respectively.. He also received his MBA degree in Power Management from National Power Training Institute, Faridabad, under the Ministry of Power, Government of India. Presently he is Assistant Executive Engineer in Tamil Nadu Electricity Board, Chennai (State Power Utility restructured into TANGEDCO and TANTRANSCO)) and persuing the Ph.D degree at Anna University, India. His research topic includes power system operation and control.

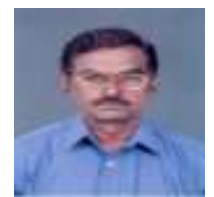

K.Thanushkodi received the BE degree in Electrical \& Electronics Engineering and M.Sc (Engg) degree from Madras University, Chennai in 1972 and 1976 respectively and the Ph.D degree in Electrical and Electronics Engineering from Bharathiar University, Coimbatore, India in 1991.He is with Akshaya College of Engineering and Technology, Coimbatore. His research interests include computer modeling and simulation, computer networking and power systems. 